\title{
Embryonic development of the sea bass Dicentrarchus labrax
}

\author{
Patricia Cucchi · Elliott Sucré • Raphaël Santos • \\ Jeremy Leclère • Guy Charmantier • \\ René Castille
}

Received: 22 February 2011/Revised: 20 June 2011/Accepted: 22 June 2011 / Published online: 31 July 2011

(C) Springer-Verlag and AWI 2011

\begin{abstract}
The embryonic development of the sea bass Dicentrarchus labrax during the endotrophic period is discussed. An 8 cells stage, not reported for other studied species, results from two rapid successive cleavages. Blastula occurs at the eighth division when the embryo is made of 128 cells. During gastrulation, the infolded blastoderm creates the endomesoblastic layer. The Kupffer's vesicle is reported to drive the left/right patterning of brain, heart and digestive tract. Heart formation starts at 8 pairs of somites, differentiation of myotomes and sclerotomes starts at the stage 18 pairs of somites; main parts of the digestive tract are entirely formed at 25 pairs of somites. At 28 pairs of somites, a rectal region is detected, however, the digestive tube is closed at both ends, the jaw appears the fourth day after hatching, but the mouth is not opened before the fifth day. Although cardiac beating and blood circulation are observed, gills are not reported in newly hatched individuals; eye melanization appears concomitant with exotrophic behavior.
\end{abstract}

Keywords Embryonic development - Teleost .

Dicentrarchus labrax $\cdot$ Endotrophic period · Organogenesis

Communicated by H.-D. Franke.

Electronic supplementary material The online version of this article (doi:10.1007/s10152-011-0262-3) contains supplementary material, which is available to authorized users.

P. Cucchi $(\bowtie)$ · E. Sucré · R. Santos · J. Leclère ·

G. Charmantier $\cdot$ R. Castille

AEO Team, ECOSYM UMR 5119,

University of Montpellier 2, CNRS, IRD, IFREMER, UM1,

34095 Montpellier Cedex 05, France

e-mail: pcucchim@univ-montp2.fr

\section{Introduction}

The embryogenesis of teleosteans have been studied since Aristote realized that the majority of bony fishes are oviparous, and made some observations on the developing eggs (Oppenheimer 1936). The first figures of consecutive stages in teleostean development appear in 1,785 and color draws were made by ME Block in "Ichthyologie, ou histoire naturelle, générale et particulière, des Poissons, Berlin" besides this few detailed observations were made following the nineteenth and twentieth centuries (Oppenheimer 1936).

Since this early period, increasing attention was devoted to the embryogenesis of teleosteans, but only few works give a detailed view of some aspects of the organogenesis. Comparative studies made on several different species provide an insight into the variety of embryonic and larval development underlining a certain homology of embryonic features between fish occupying more or less distant taxonomical positions (Yamamoto 1975; Russel 1976; Divanach 1985; Marangos et al. 1986). More recently, several studies have proposed more detailed view of the embryogenesis of teleosts including new interesting data concerning the organogenesis (Kimmel et al. 1995; Hill and Johnston 1997; Hall et al. 2004; Iwamatsu 2004; Liew et al. 2006; Korzelecka-Orkisz et al. 2010).

Discrepancies in data have not allowed drawing a descriptive cell fate map on morphological changes common to different species. The differences in timing and sequence of the "shield" stage reported for the medaka Oryzias latipes (Iwamatsu 2004) and the zebrafish Danio rerio (Kimmel et al. 1995) underline the particular development of each species. On the whole, the embryonic patterns reported for the studied teleosts show close related analogies (Yamamoto 1961; Russel 1976; Kimmel et al. 1995). 
The sea bass Dicentrarchus labrax is a teleostean of high commercial value in Mediterranean fish farming and most European fisheries (FAO, CE). Its zootechnical handling is well mastered (Barnabé 1978, 1983, 1986; Barnabé and René 1972; FAO 1997; Johnson and Katavic 1986).

In natural conditions, this euryhaline species is reported to spend embryonic and larval phases in marine environments (salinity $=38 \%$ ) before the migration of juveniles to coastal zones, estuarine, and lagoons (Jennings and Pawson 1992; Varsamos et al. 2002), where salinity conditions may greatly fluctuate from hypersaline environments (up to $40 \%$ ) to freshwater $(0.17 \%$ ).

Preliminary approaches on the embryonic development of D. labrax (Barnabé 1986; Marangos et al. 1986) brought only little information concerning the organogenesis. More recently, a more detailed study on the development of this species under different temperature conditions provided some new information on the chronology of the different embryonic steps (Saka et al. 2001).

At the histological level, embryonic and post-embryonic developments of the forming digestive system is described, including the emergence of pharynx, gut, and digestive glands (Giffard-Mena et al. 2006; Sucré et al. 2009).

A better knowledge of timing and event sequence should permit to determine the set-up and functionality of the cells and tissues involved in adaptation processes observed in early life phases of D. labrax.

The aim of this study is thus to investigate the early development of D. labrax in order to accurate the chronology of the main ontogenetic phases. A special attention is given to the description of organogenesis events; affecting notochord, gut, Kupffer's vesicle, heart, nervous system, eye, and otic capsules. Descriptive data are expected to serve as a guide for marine biologists and fish farmers working on D. labrax embryos. We have summarized the early developmental stages in Tables 1, 2, 3, and 4 in electronic supplementary material (Online Resource).

\section{Materials and methods}

Eggs from D. labrax were collected at the fish farm "Poissons du Soleil", (Balaruc les Bains, Hérault, France), from late January to early April. They were transferred to the laboratory (Montpellier University) and maintained in glass containers at a density of about $500 \mathrm{eggs} / \mathrm{L}$. Two series of "in vitro" fertilized eggs were also furnished by IFREMER (Institut Français pour la Recherche et l'Exploitation de la Mer; Palavas les Flots, Hérault, France).

Incubation was performed under dark conditions, in 1-L glass beakers at $15^{\circ} \mathrm{C}$ using a MIR-153 Sanyo incubator.
Sea water (SW) showing a salinity range from 37 to 38 ppm was changed twice a day.

Fertilized eggs at different stages of development, immersed in SW, were selected using a magnifying stereoscope, prior to be carefully recovered with micro-tools enabling the orientation of the egg sphere for photographic purposes. To facilitate the orientation of the embryos, methyl cellulose (3\%) was added to SW to increase viscosity.

The embryonic development was recorded using a M420 Leica magnifying stereoscope fitted with a DC300F Leica camera driven by an FW 4000 Leica Software. Pictures were obtained using a Corel Photo-Paint II Software in order to adjust color mode in gray scale ( 8 bit) and tone curve. The image was cropped to show the main subject only.

\section{Results}

General developmental patterns, from zygote to exotrophic larvae

Following fertilization, the translucent ovum becomes a fertilized egg, a small spherical body of $1.3 \mathrm{~mm}$ in diameter. The structure is surrounded by an external envelope, the chorion, separated from the inner vitellin membrane by the peri-vitellin space resulting from the cortical reaction preceding the zygote formation (Online Resource: Table 1). Yolk mass decreases progressively, before its complete exhaustion 7 days after the hatch.

The zygote $(\mathrm{Z}), 0 \mathrm{~h}$ post-fertilization $(0 \mathrm{hpf})$, may be defined as a fine layer located over the yolk forming the blastoderm at the animal pole of the fertilized egg; the yolk exhibits one or more floating oil globules (Fig. 1a).

The first cleavage ( $1.5 \mathrm{hpf})$ divides the blastoderm into two blastomeres (2C) of same volume (Fig. 1b, c). The second division (1.7 hpf) occurring on a perpendicular plane related to the first one results into four opaque cells (4C) of equivalent size (Fig. 1d).

"Stage 6/8": The subdivisions into 8 cells results from two successive cleavages, generally non-reported during the embryogenesis of other studied fish species, probably due to the extreme short lasting of the event. The motion dynamics involves the lowering of adherence of the two angle-opposed blastomeres $\mathrm{A}$ and $\mathrm{C}$ allowing the other two, B and D, to increase their membrane contact. The division yielding stage 6 (6C, $2.9 \mathrm{hpf}$ ) (Fig. 1e) starts at the external side of cells $\mathrm{A}$ and $\mathrm{C}$ (Online Resource: Table 1.I.4). The subsequent stage 8 ( $8 \mathrm{C}, 3.2 \mathrm{hpf})$ results from the cleavage of cells B and D starting at their contact zone (Fig. 1f; Online Resource: Table 1.I.4). 

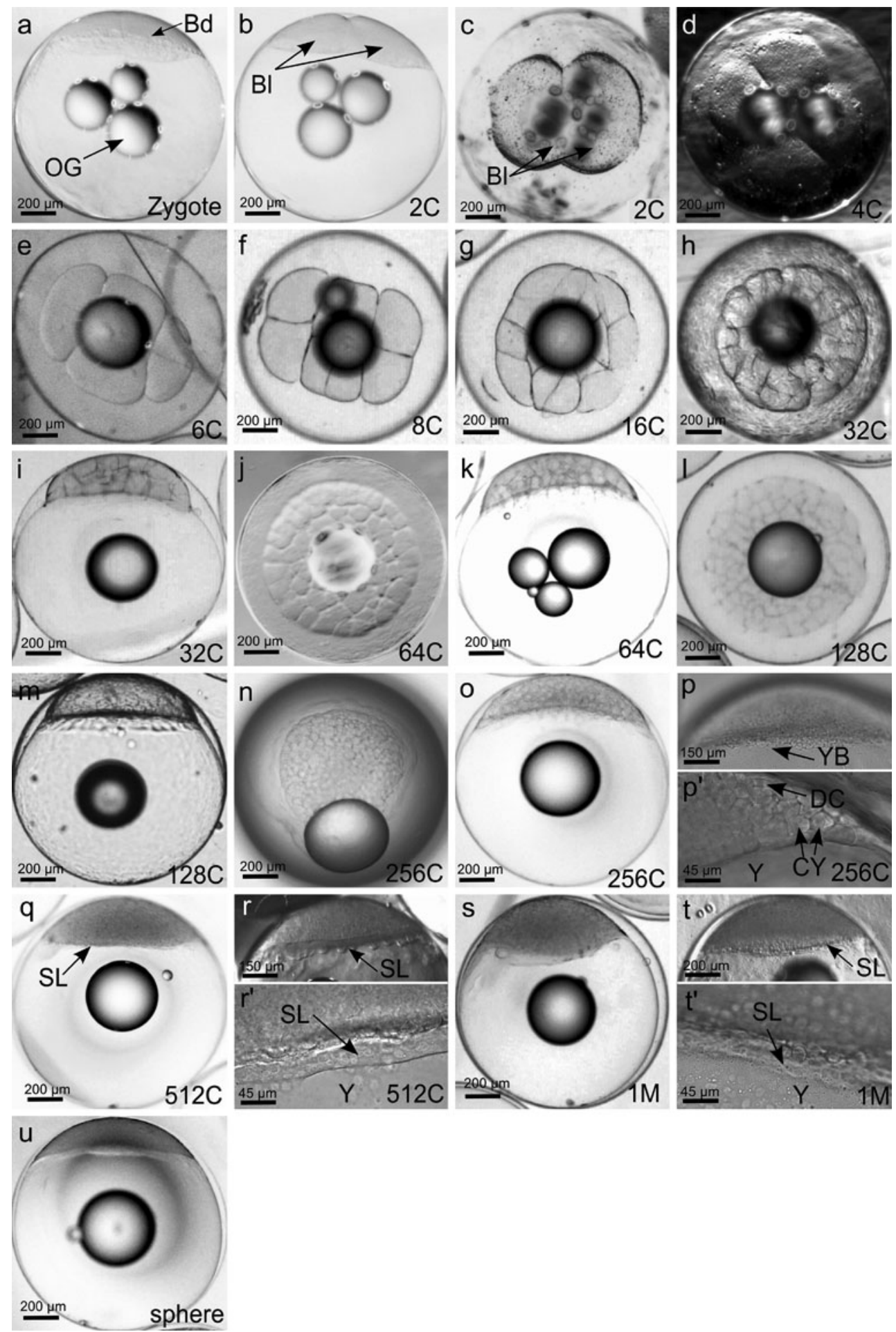

Fig. 1 Early cleavage. From $\mathrm{Z}$ (a) to Sphere (u). $1 C 1$ cell, $B d$ blastoderm, $B l$ blastomer, $D C$ dome cells, $C Y$ cells in contact with yolk, $I M 1,000$ cells, $O G$ oil globule, $S L$ syncytial layer, $Y$ yolk, $Y B$

yolk-blastoderm contact zone. Meridian view (a, b, i, k, m, o, p, p', $\left.\mathbf{q}, \mathbf{r}, \mathbf{r}^{\prime}, \mathbf{s}, \mathbf{t}, \mathbf{t}^{\prime}, \mathbf{u}\right)$; polar view (c, d, e, f, $\left.\mathbf{g}, \mathbf{h}, \mathbf{j}, \mathbf{l}, \mathbf{n}\right)$; enlarged details $\left(\mathbf{p}, \mathbf{p}^{\prime}, \mathbf{r}, \mathbf{r}^{\prime}, \mathbf{t}, \mathbf{t}^{\prime}\right)$

The fourth cleavage (16C, $4.2 \mathrm{hpf}$ ) divides the blastoderm which displays a regular rectangular shape into 16 blastomeres (Fig. 1g) lined by the onset of the periblast. The 4 central cells split off the yolk forming the space at

the origin of the primary blastocoel; their cleavage occurs on a latitudinal plane creating thereby a central diblastic structure. The cleavage of the 12 marginal cells occurs very likely on a meridian plane, increasing the blastoderm area. 
Beyond this stage, the division planes become irregular and less observable.

At stage 32 (32C, $5 \mathrm{hpf}$ ), due to the reduced size of the resulting blastomeres (Fig. 1h, i), the blastoderm area remains unchanged. Its increased thickness observed at stage 64 (64C, $5.8 \mathrm{hpf})$, indicates the setup of a stratified structure (Fig. 1j, k).

The onset of the blastula probably occurs at the eighth division (128C, $6.9 \mathrm{hpf}$ ) when the embryo is made of 128 cells (Fig. 11, m), supposing that cell divisions are still synchronized at this step of development. The cap-like structure issued from the mitotic cycle yielding 256 cells (256C, $7.6 \mathrm{hpf}$ ) exhibits an irregular stratified configuration (Fig. 1n, o). Important modifications occur during this transition, in particular the limit between the blastoderm and the yolk is more discernible prefiguring the syncytial layer (Fig. 1p, p'); it corresponds to a fine strip inserted between the periblast and the rim of blastoderm, which appears as a regular circle whose perimeter increases following an epibolic movement over the yolk. The cells in contact with the yolk are larger than those of the upper part of the dome (Fig. 1p, p'). At 512 cells (512C, 8.5-9 hpf) (Fig. 1q), the contact zone between yolk and blastoderm becomes flat due to the setup of the syncytial layer (Fig. 1r, r'). At this stage, the stereoscope indicates that the blastoderm becomes transparent revealing a cavity beneath the dome.

At a stage of about 1,000 cells (1 M, 10-15 hpf) (Fig. 1s), the periblast underlying the segmentation cavity is differentiated into two regions, the internal vitelline which persists until the eclosion, and the external region, in contact with the syncytial layer. The second, involved in the epibolic movements yielding the different embryonic layers, shows an ill-defined cellular border between the yolk and the developing blastoderm. The evolution of this transitional zone within the interval 256-1,000 cells is illustrated on Fig. 1t, t'.

During the gastrula phase, the dorso-ventral axis of the embryo can be determined and a series of morphological changes are described.

The epibolic movement of blastodermal proliferating cells envelops the yolk. Both embryo and vitellin mass evolve into a well-defined spherical structure (Fig. 1u), prior forming a "dome" (20 hpf) (Fig. 2a). At this stage, the forming embryo is first orientated according to a cephalo-caudal axis, while its area reaches $20 \%$ epiboly (Fig. 2b). At the "germinal ring" stage (Fig. 2c, d); the blastoderm expands over the yolk (21.5 hpf). A side view (Fig. 2d) shows the regular thickness of the blastoderm.

The expansion of the periblast over the yolk enhances the blastoderm area forming a "shield" (Fig. 2e, f) resulting from marginal periblastic folds (Fig. $2 \mathrm{~g}-\mathrm{k}$ ). This corresponds to the start point of infolding and convergence movements yielding the endo-mesoblastic layer (23 hpf) and determining thereby the posterior end of the embryo. At the onset of gastrulation, the embryo shows well-defined cephalic and caudal regions (Fig. 21) while epiboly reaches $60 \%$ (27 hpf). A meridian view (Fig. $2 \mathrm{~m}$ ) clearly exhibits the "bracket limit" marking the border between epiblast and hypoblast, and permitting thereby to note the rapid evolution of gastrulation marked by the setup of neurulation. At the stage corresponding to $90 \%$ epiboly (30 hpf), the evolution of endo-mesodermal layers initiates the formation of the blastopore (Fig. 2n). The cephalic region is already recognizable at the "bud" step (31 hpf) (Fig. 2o). The dorso-ventral and antero-posterior axis are defined. A view from the anterior end (Fig. 2p) shows the lateral advancing of infolding concomitantly to the progression of epiboly on both sides of the blastoderm.

The segmentation period is characterized by the formation of paired metamerized structures, the somites (Fig. 3a-k). At 32 hpf, the embryo lengthens and a thin membrane-like feature appears surrounding the oil drop. The first pair of somites, indicated by a thin furrow, is located at the anterior third of the embryo (Fig. 3a). Main organogenesis patterns occurring following the embryonic segmentation are described in "See Organogenesis".

At the stage 18 pairs of somites (55 hpf) (Fig. $3 \mathrm{f}$ ), the number of chromatophores and iridophores already observed at 5 pairs stage is highly increased. A dark mass of cells, located immediately beneath the chord, indicates the set up of pronephric and haematopoietic tissues. Typical herringbone-shaped musculature, corresponding to the myotomes occurs during this stage.

At the stage 28 pairs of somites (Fig. 3k), the increase in pigmentation indicates the imminence of hatching (Fig. 31). Pharyngeal arches III-VI are at the origin of gills, however, the rudiments of gill filaments are not observed at the onset of hatching, which occurs within 92-93 hpf. Newly hatched larva shows numerous chromatophores invading the optic capsules and covering the skin on the dorsal region and the walls of the yolk vesicle (Fig. 3m).

One day after hatch ( $1 \mathrm{dph})$, the yolk sac is reduced by about $50 \%$ of its initial size (Fig. 3n). The translucent dorsal fin extends along the dorsal side between the nape and the sketch of the tail.

Swimming movements are jerky and uncontrolled, such behavior ceases with the progressive development of dorsal and ventral fins (3-4 dph) (Fig. 3o, p). The former is still unique while the latter extends from the rectal tip to the tail end in which caudal fin rays and chromatophores are noticeable. Two days after hatching, the oil drop occupies $50 \%$ of the reduced yolk sac; rudimentary pectoral fins appear behind the gill arches; swimming movements are more coordinated. 

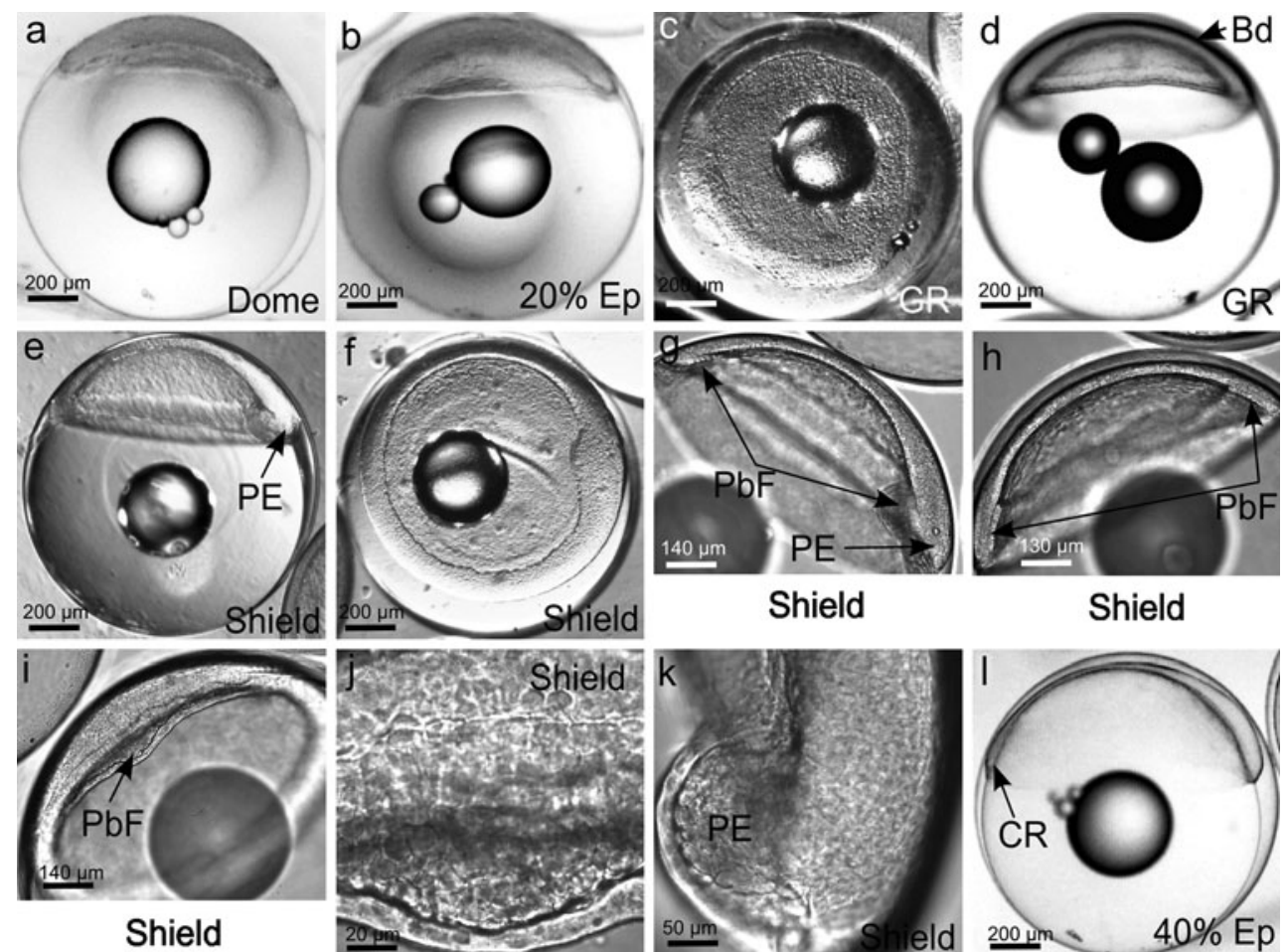

Shield

Shield
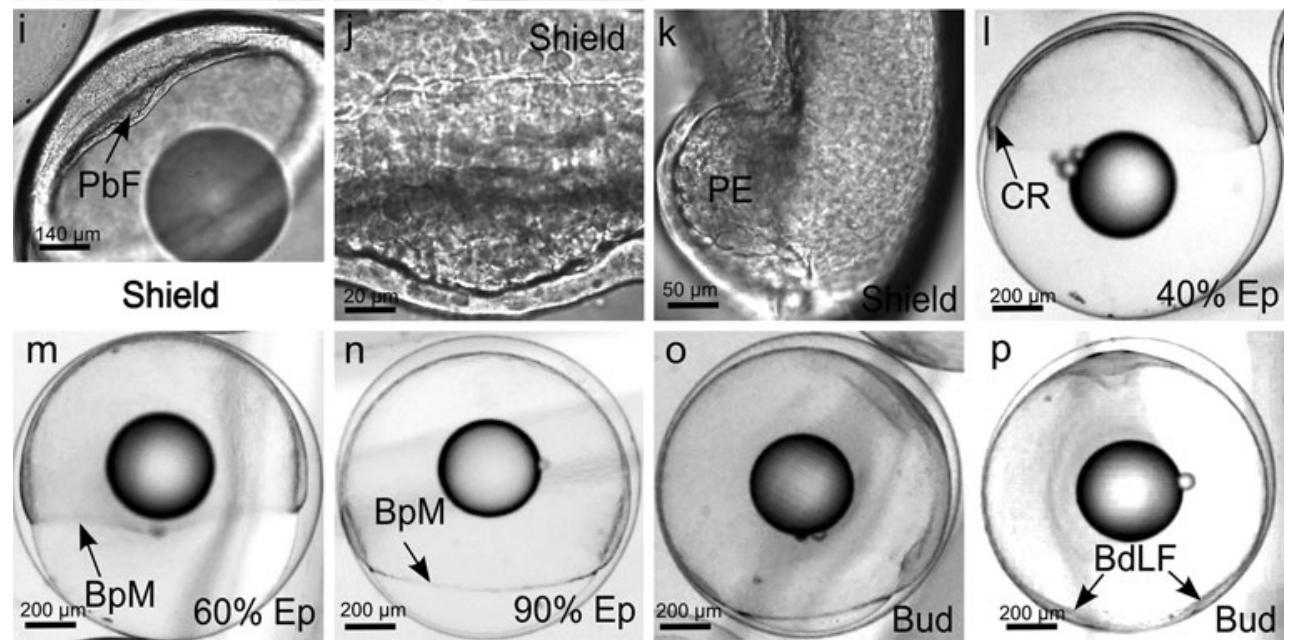

Fig. 2 Late cleavage. From dome (a) to bud (p). $B d$ blastoderm, $B d L F$ blastoderm lateral folds, $B p M$ blastopore margin, $C R$ cephalic posterior end. Meridian view (a, b, d, e, $\mathbf{g}, \mathbf{h}, \mathbf{i}, \mathbf{j}, \mathbf{k}, \mathbf{l}, \mathbf{m})$; lateral view $(\mathbf{n}, \mathbf{o}, \mathbf{p})$; polar view (c, f); enlarged details $(\mathbf{g}, \mathbf{h}, \mathbf{i}, \mathbf{j}, \mathbf{k})$

On the fifth day ( $5 \mathrm{dph})$, the yolk vesicle is practically restricted to the oil drop (Fig. 3q). The occurrence of the jaw precedes the mouth opening enabling the starting point of exotrophy.

Organogenesis

\section{Notochord}

At $32 \mathrm{hpf}$, the chord is already discernible (Fig. 4a). The chord structure becomes more visible at the occurrence of 6 pairs of somites and later over the metamerization (Fig. 4b-e). A dorsal view of the tail of an embryo at 20 pairs of somites shows the chord still flanked by undifferentiated somatic blastema (Fig. 4d). The cells of the anterior chord of a hatching time stage exhibit vacuole-like structures, forming a rod made of irregular cells indicating the typical shape of mature chord (Fig. 4e).

\section{Kupffer's vesicle and gut}

Concomitantly with the occurrence of 3 pairs of somites (36-38 hpf) there is a fluid-filled organ located at the ventral side of the caudal region, the Kupffer's vesicle, observable between the stages 3 and 13 pairs of somites (Fig. 4f-h).

The gut becomes noticeable at 22 pairs of somites, showing an enlarged part corresponding to the developing midgut (Fig. 4i, j). Thus, the main parts of the digestive tract are entirely formed at 25 pairs of somites.

\section{Heart}

Heart formation starts at about 10 pairs of somites (Fig. 4k). At this stage, the heart is an elongated structure occupying the pericardial sac located ventrally just behind the optic vesicle, underlying the foregut region. Within the 

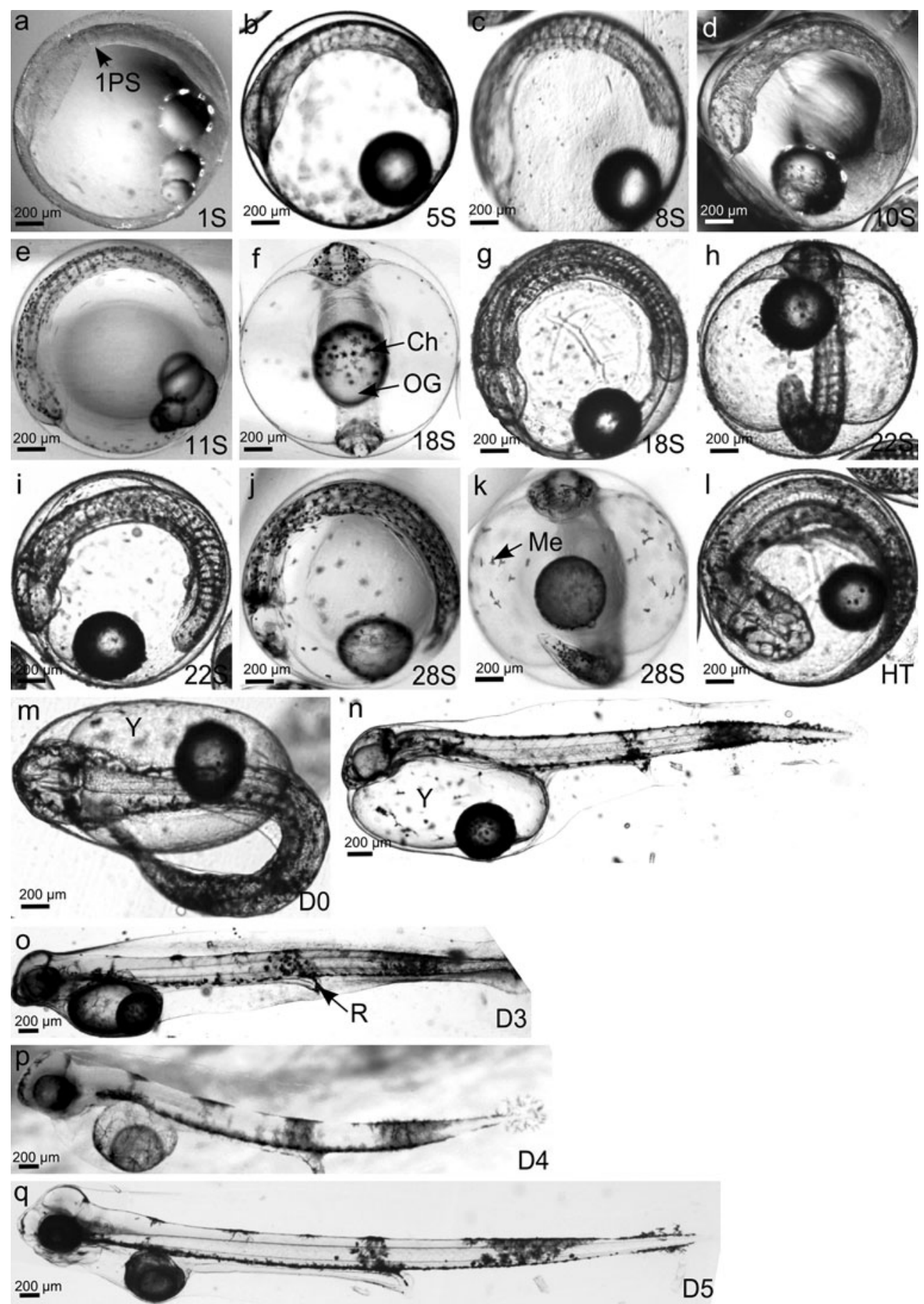

Fig. 3 Somitogenesis. From 1 pair of somites (a) to 5 days post-hatching (q). $C h$ chromatophores, $D$ days post-hatching, $O G$ oil globule, $R$ rectum, $S$ somites

interval between stages 13-14 pairs of somites, it evolves into a straight hollow tube (Fig. 41). At 21 pairs of somites, the heart bends showing 2 chambers (Fig. $4 \mathrm{~m}$ ) Cardiovascular ducts and aortic arches (III-IV) appear at 22 pairs of somites (72-73 hpf) (Fig. 4n, o) stage at which the flexure of the tail occurs. At a stage of 24-25 pairs of somites, a septum-like structure separates the 2 cardiac chambers yielding the ventricle and the atrium (Fig. $4 p$ ). Cardiac beating is recorded at 28 pairs of somites (79-80 hpf), blood flows, and the aortic trunk becomes recognizable (Fig. 4q). From hatching, anterior and posterior cardinal veins join Cuvier ducts leading to the sinus venosus 

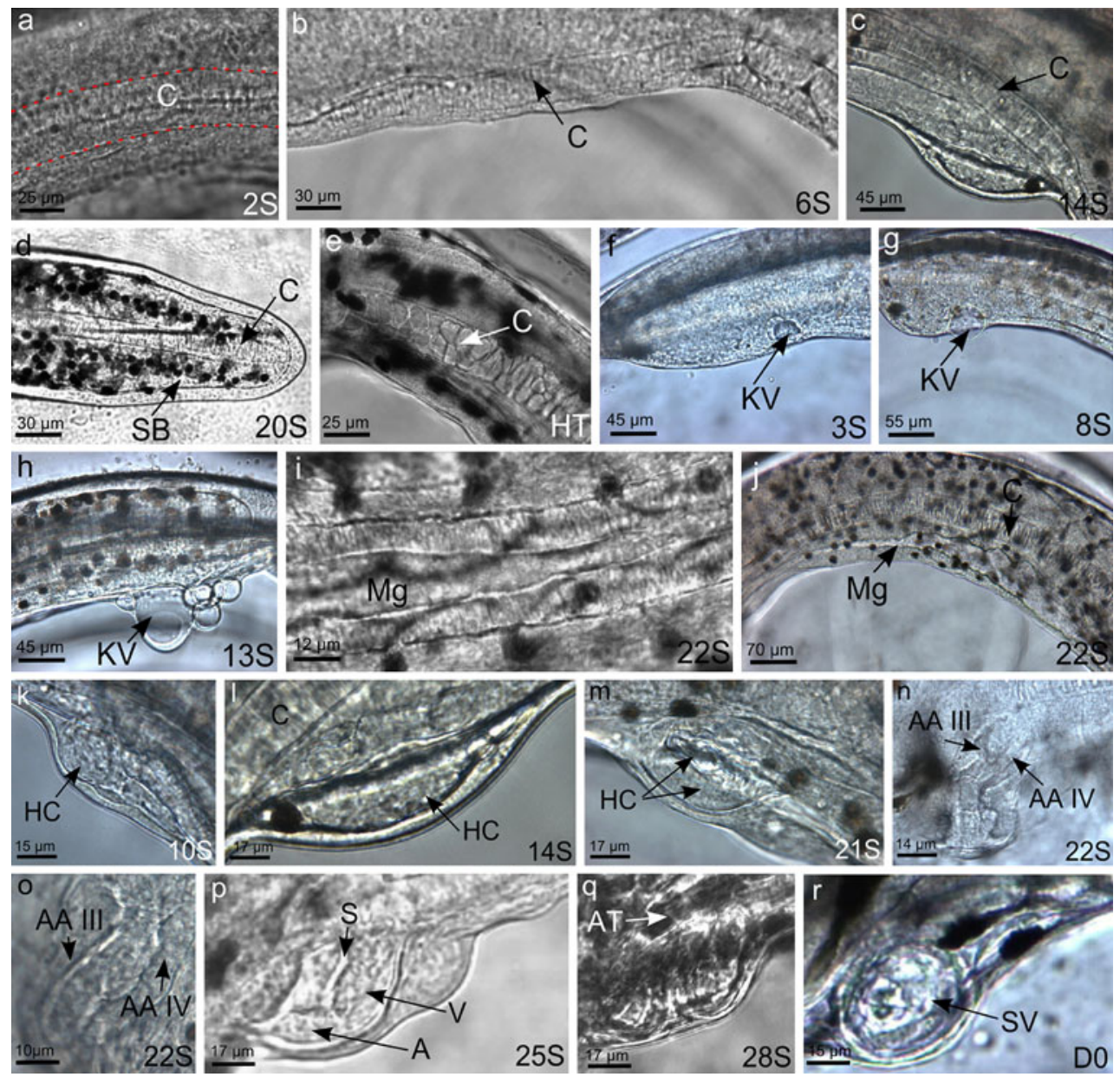

Fig. 4 Organogenesis. Notochord (a-e), Kupffer's vesicle and gut $(\mathbf{f}-\mathbf{j})$, heart $(\mathbf{j}-\mathbf{r})$. $A$ atrium, $A A$ aortic arch, $A T$ aortic trunk, $C$ chord,

$S$ septum, $S B$ somatic blastema, $K V$ kupffer's vesicle, $V$ ventricle, $S V$ sinus venosus

$H T$ hatching time, $H C$ heart chambers, $H S$ heart sketch, $M g$ midgut,

(Fig. 4r). The occurrence of bilateral aortic arches indicates the end of the pharyngula period.

\section{Nervous system}

The proencephalon, already noticeable at 3 pairs of somites, expands laterally forming two ovoid symmetrical vesicles at the origin of ocular globes ahead of the forming diencephalons (Fig. 5a). The tubular structure located behind the diencephalon corresponds to the mesencephalon recognizable at 8 pairs of somites (Fig. 5b). The rhombencephalon represents the posterior end of the brain just before the starting point of the spinal medulla; rhombomeres I-IV are reported on a 14 pairs of somites embryo, rh I-rh III are noticeable at hatching time (Fig. 5c-e).

The encephalon, resulting from the cavitation of the neural keel evolves, at 22 pairs of somites, into a hollow straight tube broader at in the cephalic region. The diencephalon and telencephalon are easily distinguishable just before hatching (Fig. 5c).

\section{Otic capsule}

Otic capsules appear at 14 pairs of somites (Fig. 5f), two pairs of otoliths are clearly visible (Fig. 5 g). Facing the third rhombomere of a hatching time embryo, the otic capsule containing two otoliths is clearly visible (Fig. 5d). A more detailed view shows the otic capsule containing a pair of otoliths (Fig. 5h). Two days after hatching the cartilage of the otic capsule is formed (Fig. 5i). Semicircular canals are observed since the fourth day ( $4 \mathrm{dph})$ (Fig. 5j, k).

\section{Eye}

The optic capsules appear concomitantly with the closure of the blastopore (39-41 hpf). The optic primordium is observed at 3 pairs of somites (Fig. 5a), and optic capsules may be clearly identified at 4 pairs of somites (Fig. 51, m). Crystalline lenses do not occur before the stage 11 pairs of somites (Fig. 5n) (43-45 hpf). The optic capsules result 
Fig. 5 Organogenesis. Nervous system (a-e), otic capsule (f-k), eye (l-t). Ca cartilage, $C L$ crystalline lenses, Co choroid, Cor cornea, $D e$ diencephalon, $I r$ iridophores, $M e$ mesencephalon, $O C$ otic capsule, $O p C$ optic capsule, Ot otoliths, $P e$ proencephalon, $P h$ pharyngula, $R b$ rhombomere, $R C$ retina chamber, $R e$ rhombencephalon, $\mathrm{ScC}$ semicircular canal, $T e$ telencephalon
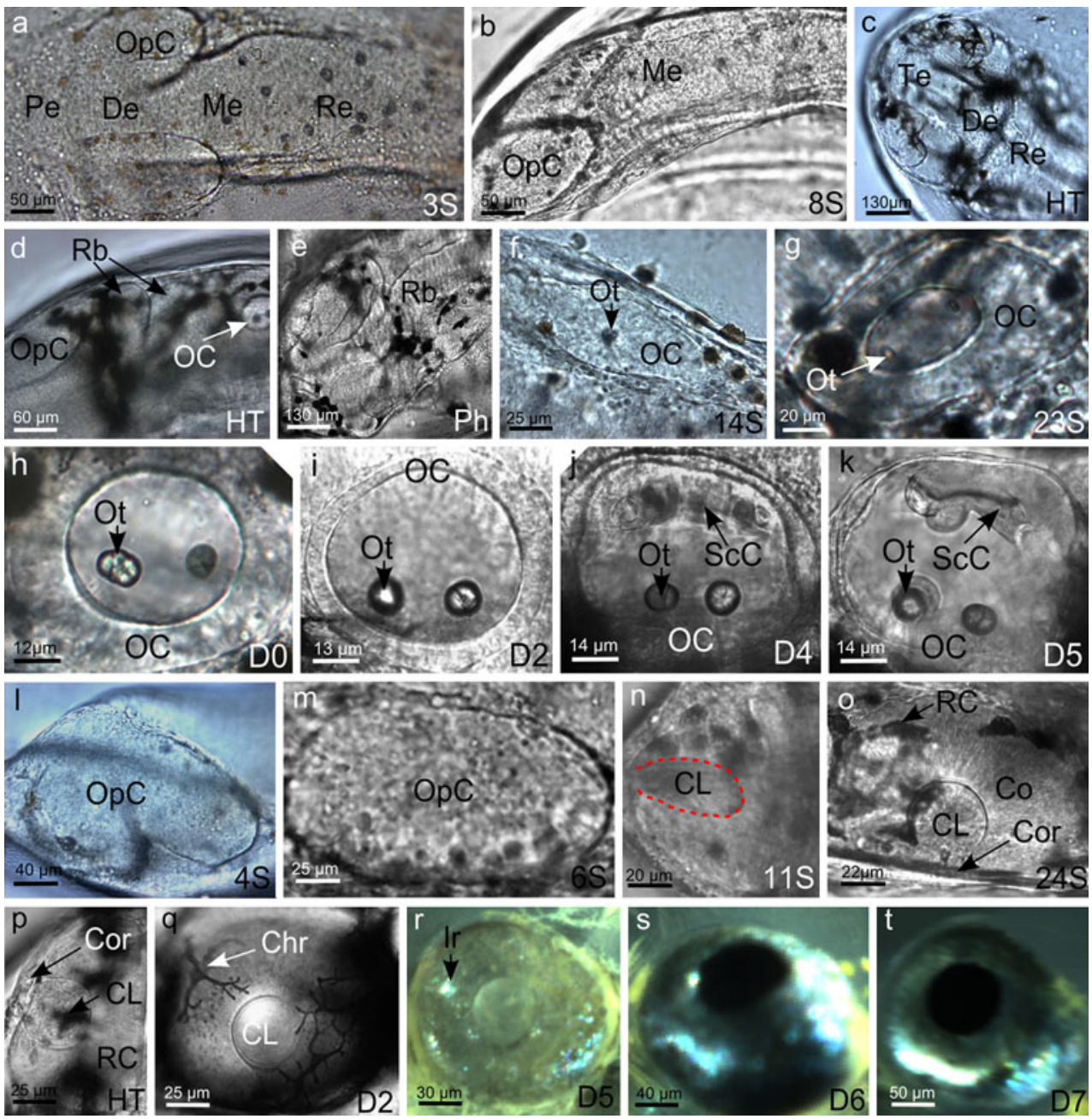

from the infolding of the ectoblast on both sides of the forming diencephalon; this process enables the formation of the crystalline lenses, the choroid and the retina chamber (Fig. 5o, p). The cornea results of the ectoderm covering the infolded capsule. Once the infolding of crystalline lenses is achieved (Fig. 5p), melanophores invade the surface of the cornea (Fig. 5q), before their progressive retraction to the periphery of the eye. Two days after hatching melanophores and xanthophores cover the eye. The ocular globe of a 2 days-hatched larva exhibits a brilliant external aspect (Fig. 5q-s), due to the occurrence of numerous iridophores, but the dark retinal pigmentation is not observed before 6 days after hatching (Fig. $5 \mathrm{~s}, \mathrm{t}$ ).

\section{Discussion}

Furthermore, the origin of the biological material, there is a number of abiotic factors (temperature, salinity, photoperiod, population density...) influencing the timing of embryonic development in laboratory conditions, that could explain the series of chronological discrepancies between these observations and those reported in the literature (Barnabé 1978; Marangos et al. 1986; Saka et al. 2001).

Common to most fish eggs, the chorion has a major impact on water exchange particularly important to the adaptation to pelagic conditions (Blaxter 1969); in the nature its withdrawal results of the activity of the hatching enzyme produced by the embryo at a stage preceding the hatching (Yamamoto 1975; Mellinger 2002). In general, the yolk is homogeneous, non-pigmented and translucent, showing however a motile oil globule. The opacity of this membrane in certain species needs its removal for to obtain reliable images, however, the chorion of D. labrax smooth and quite transparent, provides good enough stereoscopical images.

Several accurate observations made on the fertilized egg of D. labrax have revealed the regular occurrence of an additional six cells stage within the third cleavage which normally yields 8 cells. An asynchrony of the mitotic rhythm of the stage 4 determines two successive well 
defined divisions leading to the appearance of a six cells stage preceding immediately the formation of the typical eight cell structure. On so far, such a particularity has not been reported before, including in the recent detailed studies on the embryonic development of SW (Hill and Johnston 1997; Hall et al. 2004; Liew et al. 2006) and FW (Kimmel et al. 1995; Iwamatsu 2004; Korzelecka-Orkisz et al. 2010) teleosteans. This lack of data is probably due to the extremely narrow time interval at which these divisions could occur.

The thinning of blastoderm and its spreading over the forming syncytial layer are responsible of the epibolic movements yielding the different embryonic layers (Trinkaus 1966).

The segmentation cavity at the 16 cells stage was reported on the sea bass Serranus atrarius (Wilson 1891). This configuration observed in D. labrax, and very probably in many other teleosteans (as far as we know, not described), corresponds more precisely to the subgerminal cavity resulting of the enzymatic activity of blastomers leading to the lost of contact of the four central cells with the underlying periblast which represents an interphase between two different components: the yolk and the blastoderm (Devillers 1961). The particular shape of the periblast of $D$. labrax embryo indicates the site of enzymatic reactions enabling the transformation of yolk reserves and the transfer of digestion products to the forming embryo (Kunz 1964).

The formation of the blastocoel in D. labrax is observed at a stage matching 128 cells, the central zone of the forming blastoderm appears thickened, marking the starting point of blastulation. Disregard to rearing conditions and taxonomical criteria, comparable results are reported for the anemone fishes Amphiprion ocellaris (Liew et al. 2006) and Amphiprion chrysopterus (Allen 1972). The movements of the external periblast are very likely involved in the differentiation of the embryonic layers (Trinkaus 1984). According to this, the "germinal ring" may be considered as the onset of gastrulation. During this step, the blastoderm becomes thin and expands by epiboly over the yolk, infolding at its periphery, creating thereby the characteristic circular thickness leading to the setup of the endomesoblastic layer. In fact hypoblast derivatives mesoderm and endoderm are not separated forming thereby a unique embryonic layer, the endo-mesoderm. Such a configuration has been reported to result of the absence of the gene implicated in the formation of the three germinal layers classical of triblastic organisms (Thisse et al. 1993). The balance of the forces of adhesion of blastomeres to each other and to the syncytium, superficial tension of yolk surface, and contractility of the periblast control the form of the developing embryo (Blaxter 1969).
The fish neural tube results of cavitation of the solid neural keel, since there is no formation of a groove in the neural plate as it happens in most vertebrates (Kupffer 1868; Papan and Campos-Ortega 1994). Nevertheless, it was very hard to follow the morphogenic steps driving to the different encephalic regions on D. labrax embryos, that what explains the lack of figures illustrating this topic. In the cod Gadus Morhua, soon after the beginning of somite formation the anterior neural plate swells and distends into the primordium of the brain. As epiboly proceeds, neural plate cells extend ventrally to form afterward a solid neural rod. A central lumen, the neurocoel, originates by cavitation rather than infolding, as reported in avian and mammalian systems (Hall et al. 2004).

The Kupffer's vesicle, a vestige of the archenteron (Wilson 1891), is reported to drive the left/right patterning of various organs like the brain, the heart and the digestive tract of the Zebrafish Danio rerio. The removal of the Kupffer's vesicle has provided direct evidence on these points (Essner et al. 2000). In most studied fish species, the set up of somites starts at the anterior part of the body; in general, the earliest five pairs occur within a rather short time interval (Kimmel et al. 1995). It seems not unreasonable to believe that the formation of somites may also be related to the appearance of the Kupffer vesicle at the beginning of segmentation. These results confirm those obtained in D. rerio (Kimmel et al. 1995), G. Moruha (Hall et al. 2004), and in the medaka Oryzias latipes (Iwamatsu 2004) which described the formation of the Kupffer's vesicle following completion of epiboly.

Gut tube is known to forms all along the segmentation period (Kimmel et al. 1995; Hill and Johnston 1997; Iwamatsu 2004). In D. labrax, the characterization of midgut was obtained at 22 pairs of somites and matches histological previous results (Sucré et al. 2009). In O. latipes, Kobayashi et al. (2006) have shown that the gut formation is initialized at stage $6 \mathrm{~S}$ and ends at stage $22 \mathrm{~S}$ with a welldistinguishable midgut. In contrast, in G. morhua, the midgut was described only 2 days after hatching (Hall et al. 2004).

The "herring bone" muscular shape of most studied fish species has been reported to occur within the thirteen and the eighteen stage of the embryogenesis. The parietal musculature of $D$. labrax, observed at the stage 18 pairs of somites, suggests that the differentiation of myotomes and sclerotomes starts at this stage (Felsenfeld et al. 1991; Kimmel et al. 1995). We have no information concerning dermatomes and not any data was found in literature concerning teleost development.

Two types of branching pigmentary cells occur in the space between the periblast and the visceral cavity, the melanophores full of melanin granules and the chromatophores containing irregular lipid globules. Considering that 
during the early development, organs and tissues involved in osmoregulation are not yet functional, the increase of melanophores and other pigmentary cells at the stage $24 \mathrm{p}$ (75 h) (Balon 1977), suggests that these structures might have been implicated in ionic regulation.

Neurocoele formation in fish is consequent to cavitation of the solid neural keel, however, as in most vertebrates, the otic territory (otic placode and primary acoustic organ) results of the enhanced thickness of the posterior region of the rhombencephalon.

Heart formation in D. labrax starts at about 8 pairs of somites, stage at which the organ is a mere tubular structure located behind the mid-brain, evolving progressively into an auricular cavity; the ventricular one, not recognizable before 18 pairs of somites, takes place later. Dorsal aorta, vitello-caudal vein, and vascularization of the yolk sac become apparent at 20 pairs of somites. Although a heart beat occurs at this stage, the appearance of cardiac valves cannot be confirmed, moreover the blood is colorless and there is no evidence for a regular blood circulation before $80 \mathrm{~h}$ of development. In G. moruha, pericardial cavity is visible by 20 pairs of somites. Sporadic heart beats occur after the stage 40 pairs of somites (Hall et al. 2004).

The feeble heart beat recorded for D. labrax embryo matches the observations made during the embryonic development of other fish species like the zebrafish D. rerio, in which blood, in the short term, is not involved into gas exchange processes (Pelster and Burggren 1996; $\mathrm{Hu}$ et al. 2000). The respiratory mechanism of D. labrax is not yet fully functional at hatch as indicate the poorly coordinated opercular movements; however, these could very likely correspond to the starting point of a ventilatory activity. One may thus suppose that embryo oxygen requirements could be mainly satisfied by cutaneous exchanges (Burggren 2004), raising the question of whether gill respiration is necessary for newly hatched individuals. Hence, one may hypothesize that the embryonic heart starts to beat for convective blood flow mainly involved into angiogenesis; gases, nutrients and other circulating substances could be conveyed by passive diffusion, until the moment at which blood circulation can allow oxygen transport (Burggren 2004).

The hatching pre-larva is transparent showing however pigmented zones covering in particular the dorsal region; noticeable chord and myotomes suggest an immediate capacity of motion although the size of the yolk sac appears as a hydrodynamic disadvantage. This could in part explain the jerky movements of the new hatched individual probably related to the high loss resulting of predation in natural conditions.

The fact that retinal pigmentation is not observed before 6 days after hatching suggests that eyes melanization occurs concomitantly with the development of exotrophic behavior requiring a rapid improvement of vision. In the stinging catfish, Heteropneustes fossilis the pigment appeared in the eye $36 \mathrm{~h}$ post-hatch (Korzelecka-Orkisz et al. 2010), while in G. morhua (Hall et al. 2004) and O. latipes (Iwamatsu 2004), eye pigmentation occurs before hatching. The timing of pigmentation is probably adaptive, and could be due to the predation cost of possessing a highly reflective retina versus the necessity of a functional visual system before the starting of feeding activity. Before setting of eye pigmentation, the embryos are translucent, and thereof less vulnerable to visual predators (Blaxter 1988).

Immediately after hatch the mouth is not yet open, indicating that the endotrophic period is not achieved, moreover the synthesis of lipoprotein in the vitellin syncytium tends to increase at the end of endotrophy; besides this, the fact that the digestive tube is opened at its posterior end suggests the transit of vitellin residues preparing the gut to receive exogenous material.

Acknowledgments We thank the IFREMER "Palavas les Flots" lab and "Les poisons du Soleil" company for providing sea bass eggs with special thanks to Béatrice Chatain and her team (IFREMER Palavas), Gilles Maingon and Fredéric Ventre (Les poisons du Soleil) for their help. This work was granted by the University Montpellier 2 and the UMR 5119 ECOSYM with its CARAFON Technical Facility.

\section{References}

Allen GR (1972) The anemonefishes; their classification and biology, 2nd edn. T.F.H, Neptune City

Balon EK (1977) Early ontogeny of Labeotropheus Ahl, 1927 (Mbuna, Cychlidae, Lake Malawi) with a discussion on advances protective styles in fish reproduction and development. Environ Biol Fishes 2:147-176

Barnabé G (1978) Etude dans le milieu naturel et en captivité de l'éco-éthologie du loup Dicentrarchus labrax (L) (Poisson serranidae), à l'aide de nouvelles techniques. Ann Sci Nat Zool 20:423-502

Barnabé G (1983) Mass rearing of Dicentrarchus labrax (L) larvae with plankton collected from oxidation ponds. In: Stickney R, Meyers P (eds) Proceedings of warmwater fish culture workshop. Louisiana State University, Baton Rouge, pp 83-91

Barnabé G (1986) L'élevage du loup et de la daurade. In: Barnabé G (ed) Aquaculture, vol 2. Tec et Doc, Paris, pp 627-666

Barnabé G, René F (1972) Reproduction controlée du loup Dicentrarchus labrax (Linné) et production en masse d'alevins. CR Acad Sci Paris 275 D: 2741-2744

Blaxter JHS (1969) Development: eggs and larvae. In: Hoar WS, Randall DJ (eds) Fish physiology III. Academic Press, New York, pp 177-252

Blaxter JHS (1988) Pattern and variety in development. In: Hoar WS, Randall DJ (eds) Fish physiology XI. The physiology of developing fish. Part A. Eggs and larvae. Academic Press, New York, pp 1-58

Burggren WW (2004) What is the purpose of the embryonic heart beat? Or how facts can ultimately prevail over physiological dogma. Physiol Biochem Zool 77:333-345 
Devillers C (1961) Structural and dynamic aspects of the development of the teleostean egg. Adv Morphogenes 1:379-428

Divanach P (1985) Contribution à la biologie et à l'élevage de six sparidés méditerrannéens: Sparus aurata, Diplodus sargus, Diplodus vulgaris, Lithognathus mormyrus, Puntazo puntazo (Poissosns Téléostéens). Thèse d'Etat. Univ Sci Tech du Languedoc. Montpellier (France)

Essner J, Branford WW, Zhang J, Yost HJ (2000) Mesoderm and leftright brain, heart and gut development are differentially regulated by pitx2 isoforms. Development 127:1081-1093

FAO (1997) Review of the states of world aquaculture. In: FAO fisheries department. FAO fisheries circular 886. Rev 1 FAO, Rome

Felsenfeld Al, Curry M, Kimmel CB (1991) The fub 1 mutation blocks the initial myofibril formation in zebrafish muscle pioneer cells. Dev Biol 148:23-30

Giffard-Mena I, Charmantier G, Grousset E, Aujolat F, Castille R (2006) Digestive tract ontogeny of Dicentrarchus labrax : Implication in Osmoregulation. Dev Growth Differ 48:139-151

Hall TE, Smith P, Johnston IA (2004) Stages of embryonic development in the Atlantic cod Gadus morhua. J Morphol 259:255-270

Hill J, Johnston IA (1997) Photomicrographic atlas of Atlantic herring embryonic development. J Fish Biol 51:960-977

Hu N, Sedmera D, Yost HH, Clark EB (2000) Structure and function of the developing zebrafish heart. Anat Rec 260:148-157

Iwamatsu T (2004) Stages of normal development in the medaka Oryzias latipes. Mech Dev 121:605-618

Jennings S, Pawson MG (1992) The origin and recruitment of bass Dicentrarchus labrax, larvae to nursery areas. J Mar Biol Assoc UK 72:199-212

Johnson DW, Katavic I (1986) Survival and growth of sea bass (Dicentrarchus labrax) larvae as influenced by temperature, salinity and delayed initial feeding. Aquaculture 52:11-19

Kimmel C, Ballard W, Kimmel S, Ullman B, Schilling T (1995) Stages of embryonic development of the Zebrafish. Dev Dyn 203:253-310

Kobayashi D, Jindo T, Naruse K, Takeda H (2006) Development of the endoderm and gut in medaka, Oryzias latipes. Dev Growth Differ 48:283-295

Korzelecka-Orkisz A, Smaruj I, Pawlos D, Robakowski P, Tañski A, Szulc J, Formicki K (2010) Embryogenesis of the stinging catfish Heteropneustes Fossilis (Actinopterygii: Siluriformes: Heteropneustidae). Acta Ichthyol Pisca 40:187-197

Kunz Y (1964) Morphologische studien über die embryonale und postembryonale Entwicklung bei Teleostiern mit besonderer Berucksichtigung des Dottersystems und der Leber. Rev Suisse Zool 71:445-452

Kupffer C (1868) Beobachtungea uber die Entwicklung der Knochenfische. Arch Mikrob Anat 4:249-272
Liew HJ, Ambak MA, Abol-Munafi AB, Chuah TS (2006) Embryonic development of Clownfish Amphiprion ocellaris under laboratory conditions. J Sustain Sci Manag 1:64-73

Marangos C, Yagi H, Ceccaldi HJ (1986) The role of temperature and salinity on hatching rate and morphogenesis during embryo development in Dicentrarchus labrax (Linnaeus 1758) (Pisces Teleostei Serranidae). Aquaculture 54:287-300

Mellinger J (2002) L'oeuf et ses enveloppes. In: Mellinger J (ed) Sexualité et reproduction des poissons, CNRS Editions, Paris, pp 101-112

Oppenheimer JM (1936) Historical introduction to the study of teleostean development. Osiris 2:124-148

Papan C, Campos-Ortega J (1994) On the formation of the neural keel and neural tube in the Zebrafish Danio (Brachydanio) rerio. Roux Arch Dev Biol 203:178-186

Pelster B, Burggren WW (1996) Disruption of haemoglobin oxygen transport does not impact oxygen-dependent physiological processes in developing embryo of zebrafish (Danio rerio). Circ Res 79:358-362

Russel FS (1976) The eggs and plankton stages of British marine fish. Academic Press, London

Saka S, Firat K, Kamaci O (2001) The development of European sea bass (Dicentrarchus labrax L., 1758) eggs in relation to temperature. Turk J Vet Anim Sci 25:139-147

Sucré E, Charmantier-Daures M, Grousset E, Charmantier G, CucchiMouillot P (2009) Early development of the digestive tract (pharynx and gut) in the embryos and prelarvae of the European sea bass Dicentrarchus labrax. J Fish Biol 75:1302-1322

Thisse C, Thisse B, Schilling TF, Postlethwait JH (1993) Structure of the zebrafish snail 1 gene and its expression in wild type Spadetail and no tail mutant embryos. Development 119:1023-1215

Trinkaus JP (1966) Morphogenic cell movements. In: Locke M (ed) Major problems in developmental biology. Academic Press, New York, pp 125-176

Trinkaus JP (1984) Mechanism of Fundulus epiboly-a current view. Am Zool 24(3):673-688

Varsamos S, Diaz JP, Charmantier G, Blasco C, Connes R, Flick G (2002) Location and morphology of chloride cells during the post-embryonic development of the European sea bass Dicentrarchus labrax. Anat Embryol 205:203-213

Wilson HVP (1891) The embryology of the sea bass Serranus atrarius. Bull US Fish Comm 9:209-277

Yamamoto T (1961) Physiology of fertilization in fish eggs. Intern Rev Cytol 12:361-405

Yamamoto $T$ (1975) Introductory remarks on the Medaka. In: Yamamoto $\mathrm{T}$ (ed) Medaka, biology and strains. Yugakusya, Tokyo, pp 1-16 